\title{
ESTABLISH A CUSTOMER PROPERTY SERVICE STRATEGY FRAMEWORK
}

\author{
Hsu-Ming SHEN (1) ${ }^{*}$, Kung-Jen TU, Ting-Yi CHIANG (D) \\ Department of Architecture, National Taiwan University of Science and Technology, No. 43, Sec. 4, Keelung Rd., \\ Da-an Dist., 10607 Taipei City, Taiwan
}

Received 17 December 2019; accepted 18 January 2021

\begin{abstract}
The property management services sector in China is developing rapidly, contributing significantly to employment and income. We have made recommendations for service differentiation and low costs so that even with limited resources, property management services can distribute their services effectively, reduce unnecessary costs, and implement an optimal plan. This study helps property management service providers understand the needs and expectations of customers because it is a key factor contributing to the success of the business. Based on the consumer and service quality (SERVQUAL) theories, this study applies the fuzzy Delphi method (FDM) and the analytic hierarchy process (AHP) method to construct a quality evaluation scale for property management service companies and determine key property management service items that are valued most by customers and operators in this sector. The results show that it is feasible to determine accurately factors that are used to quantify the competitiveness of the existing market and identify improvements to ensure a win-win situation for both customers and companies in this sector.
\end{abstract}

Keywords: property management, service differentiation, management strategy, SERVQUAL, Shanghai.

\section{Introduction}

Property management service sectors are developing rapidly in China (Shanghai), contributing significantly to employment and income. This will boost the property management service market, which is seeing intense competition. The competitive nature of the market will push property management service companies to diligently manage their operations and market share in order to promote their brands and increase profits. Because service quality is a key factor that leads to customer satisfaction by reinforcing the caliber of the service and performance of the business operator, it increases efficiency and profitability (Chiang \& Perng, 2018; Parasuraman et al., 1985; Wang et al., 2015). Companies in this sector should create community and company value along with innovation and ultimate service quality so as to have a competitive advantage and achieve differentiation. Professional property management services are essential for helping customers (that is, residents) to create a pleasant, safe, and healthy living environment. To a certain extent, the service protects property value and promotes a good living environment for residents through redevelopment. It also contributes to the sustainable development of the city. Providing better service quality is an essential factor that increases customer satisfaction and improves the performance of property management service providers, ultimately increasing corporate profitability. Moreover, because consumers consider social and environmental concerns when making decisions, corporate social responsibility is a significant issue (Peloza \& Shang, 2011; Xie et al., 2019). Companies, industries, and individuals should develop key success factors, industries, and individuals. From the perspective of business disciplines, companies should focus on the key factors that make the business highly competitive. Furthermore, effective planning and management strategies should be implemented in order to enhance the probability of gaining a competitive advantage (Chen et al., 2015; Kendra \& Taplin, 2004). Understanding customers' needs and creating shared values are crucial toward establishing mutually beneficial and sustainable enterprise operations. Because many factors have to be considered in evaluation processes, there are some challenges in determining ideal evaluation indicators. Therefore, these processes require an appropriate evaluation system. This study adopted the consumer and service quality (SERVQUAL) theories, the

*Corresponding author. E-mail: D10913001@mail.ntust.edu.tw

Copyright $\odot 2021$ The Author(s). Published by Vilnius Gediminas Technical University

This is an Open Access article distributed under the terms of the Creative Commons Attribution License (https://creativecommons.org/licenses/by/4.0/), which permits unrestricted use, distribution, and reproduction in any medium, provided the original author and source are credited. 
Fuzzy Delphi method (FDM), and the Analytic hierarchy process (AHP). These form a set of criteria aggregation methods for evaluating the judgments of decision-makers, thereby enabling the assessment of each decision and the information or data based on which the decision was taken by the decision-makers. This facilitates the reorganization of decisions as one of several feasible alternatives. This research shows that when benchmarking critical property management service planning (PMSP), the PMSP-based benchmarking method is beneficial to all stakeholders in the property management sector. For example, it can help the customers (consumers and residents) or owners to measure the performance of their property management service companies. Consumers have their own unique belief systems that are influenced by their background; values and consumer behavior are derived from personal values. Therefore, this topic is gaining increasing importance in consumer research. The research hypothesis represents the difference between consumers' values and service providers' beliefs. Customers or owners should refer to and control for these indices when developing new case management. This study applied FDM to collect opinions from relevant experts and subsequently extracted critical items (Murray et al., 1985; Wang \& Peng, 2020). FDM serves as a criterion for screening the property management of community service facilities. The extracted items were then evaluated and screened on the basis of the findings of relevant studies (Ishikawa et al., 1993; Wang \& Peng, 2020). Subsequently, the AHP method was used to determine the relative weight and ranking of each evaluation criterion at each level (Al-Harbi, 2001; Saaty, 1990; Tsyganok et al., 2012). Finally, based on the results of the analysis, the study proposes factors to facilitate the evaluation of PMSP, relevant strategies, and recommendations for property management services. This study clarifies the main purpose of this review and explains the manner in which it differs from consumer theory and SERVQUAL development work. PMSP describes the elements that are essential for conducting a strong conceptual review and provides a specific set of best practices to be used to distinguish between a strong concept review and a weak one. Based on the literature on evaluation index systems for property management services, this study analyzes the problems presented in this research and makes recommendations for standard research. It also presents the indicators, indicator sources, and criteria for indicator selection and evaluation. For PMSP, these indicators are essential in order for it to continuously monitor and improve professional services. This study evaluates and compares the following key factors that serve as the basis for assessing property management services and housing suppliers before the launch of their products or services: (1) different types of community service facilities; (2) property management, rescue and education, and corporate social responsibility; and (3) PMSP. The remainder of this paper is organized as follows. The next section presents a literature review, and the subsequent section outlines the methodology, research design, and data collection. The discussion section explains the strategies that contribute to the knowledge system, to practical values, and to social values. Finally, the main conclusions of the study are presented.

\section{Literature review}

\subsection{Property management's role in promoting sustainability}

The National Association of Building Owners and Managers held its first annual convention in 1908 for the purpose of bringing together property owners and managers. Although the association's focus was on commercial buildings, it formed an apartment section in 1913 (Hopkins et al., 2017). Over the last century, the property management industry has changed dramatically. Today, it is arguably more sophisticated than in the past, with a diverse array of activities that extend well beyond building maintenance (Goss \& Campbell, 2008). For example, project managers working for property management services conduct customer market surveys, allocate budgets, negotiate business contracts, perform asset appraisals, and initiate improvement projects in addition to completing daily operational tasks (Read \& Carswell, 2019; Tu, 2017). Some property managers are even charged with developing and/or implementing corporate social responsibility and environmental sustainability platforms for the owners that they represent (Hopkins et al., 2017; Read \& Sanderford, 2018). The influx of service providers from various industries has given rise to chaos and competition. Vicious competition and price wars among the many small and medium-sized management firms has made business operations increasingly difficult. The gap in the extant research is noteworthy because these companies manage millions of apartments across the country and this number continues to grow (Chiang \& Perng, 2018; Omar et al., 2015; Read et al., 2017). Because of the lower entry barrier into the property management sector, most property services providers in China attract clients with relatively low margins for survival in the competitive market, which results in disparity of service quality. Although a great number of studies have focused on specific service sectors, there are only a few studies dedicated to the property service sector in China. Although these advances are welldocumented in the academic and professional literature, there is a lack of research specifically on the sustainability efforts of property management companies, especially from the property manager's perspective, regarding the challenges faced when considering property management sustainability initiatives. Therefore, property service management requires more in-depth research in the context of China's residential housing market. Property managers are currently promoting an increasing number of sustainability initiatives on realizing the need for preserving the 
environment. This study aims to analyze the needs of customers and the performance of property service providers in promoting more sustainable practices in the field of property management, especially multi-family housing projects in China, by examining the current market conditions and problems to identify possible solutions.

\subsection{Fuzzy Delphi method (FDM)}

The FDM, a technique that combines fuzzy set theory with the traditional Delphi method, can effectively reduce the time and cost of research as well as the ambiguity of experts' comments. Numerous possible impact factors can therefore be objectively reduced (Wang \& Peng, 2020). Zadeh (1965) proposed fuzzy set theory, which suggests that conventional scientific methods often ignore the uncertainties and ambiguities of human life. Zadeh used fuzzy set theory and adopted fuzzy logic concepts in the process (Zadeh, 1965). Murray et al. (1985) proposed the FDM by combining the Delphi method and fuzzy set theory to overcome the disadvantages of the Delphi method. Ishikawa et al. (1993) integrated expert opinions with fuzzy numbers based on the concepts of cumulative frequency distribution and fuzzy integrals. The operating procedures are as follows (Chiang, 2019; Ishikawa et al., 1993; Wang \& Peng, 2020).

\section{STEP 1: Set up influential assessment projects and decision-making groups}

The membership function is constructed using the comment set to clarify the subordination of each evaluation factor in the overall evaluation. Many membership functions are involved, such as rectangular distribution, normal distribution, and trapezoidal distribution. The FDM sets up assessment projects and applies triangular membership functions, choosing one or several of these functions according to the actual situation and providing a possible interval value. The minimum and maximum values are the most conservative and most optimistic cognitive values for the experts' quantitative score, respectively.

\section{STEP 2: Collect opinions from different groups}

To develop statistics based on assessment project " $i$ " the following is necessary: (1) collecting every expert's evaluation of the most conservative and optimistic cognitive values; (2) eliminating extreme values in two standard deviations; and (3) separately calculating the minimum $C_{U}^{i}, O_{L}^{i}$, the geometric mean of $C_{M}^{i}, O_{M}^{i}$, and the maximum $C_{U}^{i}, O_{U}^{i}$ from the remaining most conservative and optimistic cognitive values.

\section{STEP 3: Set up triangular fuzzy numbers}

The next step involves setting up triangular fuzzy numbers of the most conservative and optimistic cognitive values from every calculated assessment project " $i$ " by applying $C^{i}=\left(C_{M}^{i}, C_{U}^{i}, C_{U}^{i}\right)$ and $O^{i}=\left(O_{M}^{i}, O_{U}^{i}, O_{U}^{i}\right)$, as illustrated in Figure 1 (schematic of the FDM threshold).

\section{STEP 4: Inspect expert consensus}

- If $C_{U}^{i} \leq O_{L}^{i}$, then the value of the importance of consensus is $G^{i}=\left(C_{M}^{i}+O_{M}^{i}\right) / 2$.

- If $C_{U}^{i}>O_{L}^{i}$, and the gray zone of the fuzzy relationship $Z^{i}=C_{U}^{i}-O_{L}^{I}$ is less than $M^{i}=O_{M}^{i}-C_{M}^{i}$, which represents the interval range of the optimistic and conservative cognitive means, then $G^{i}$ equals the fuzzy set, which is computed by intersecting the relationships between two triangular fuzzy numbers and calculating the maximum value required to obtain the quantified scores.

- If $C_{U}^{i}>O_{L}^{i}$ and the gray zone of the fuzzy relationship $Z^{i}=C_{U}^{i}-O_{L}^{i}$ is less than $M^{i}=O_{M}^{i}-C_{M}^{i}$, which represents the interval range of the optimistic and conservative cognitive means, then it implies that the experts' opinions are inconsistent and the repeated questionnaire survey need to be conducted until $G^{i}$ is obtained.

The main advantages of this procedure are its ability to effectively denote a vague group of opinions and then methodically transform these opinions into quasi objective data through simple statistical operations (Wang \& Peng, 2020). Therefore, this approach can enhance criteria selection; it is not only simple but also enables all decisionmaker judgements to be managed more rapidly. The FDM can be used in collective decision making and to solve problems related to uncertainty; it can also reduce the time and costs associated with the investigation. By applying fuzzy set theory to clarify invertible fuzziness in expert interviews, researchers can obtain superior responses.

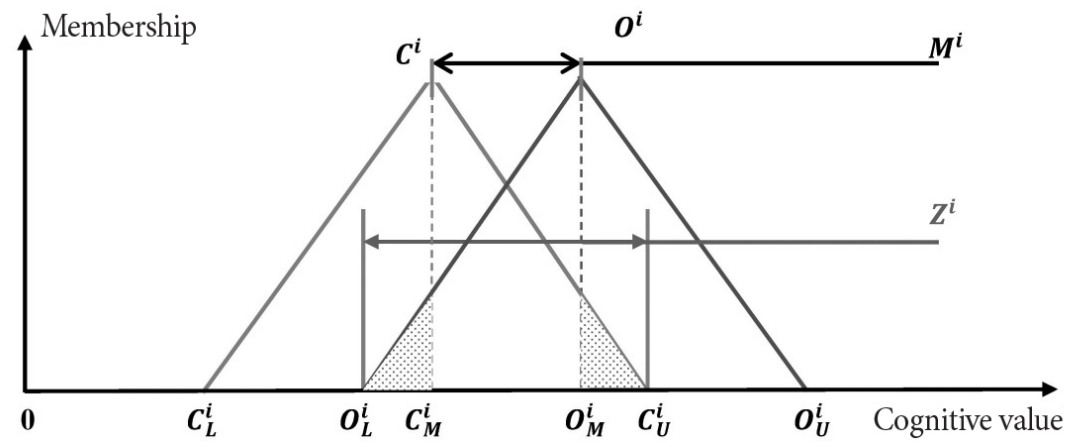

Figure 1. Schematic diagram of the FDM threshold 
Achieving superior economic effectiveness in time and costs is imperative in conducting surveys, as it ultimately will enable a reduction in the number of surveys required (Chiang, 2019; Wang \& Peng, 2020). The FDM has been widely applied to relevant research fields, e.g., real estate design (Chiang, 2019); reverse logistics (Bouzon et al., 2016); cruise tourism industry (Chen, 2016); urban sustainable development (Wang \& Peng, 2020). This study utilizes triangular membership functions and fuzzy set theory to solve a property management service project problem.

\subsection{Analytical Hierarchy Process (AHP)}

The AHP, which was introduced by Thomas L. Saaty, is the methodology used to develop the aggregation mechanism (Saaty, 1990). The AHP is a multi-criteria decision-making technique using pairwise comparisons made by the judgments of subject-matter experts to derive priority scales that measure intangibles in relative terms (Claver et al., 2020; Saaty, 1990). The AHP method is a mathematical tool for taking a systematic approach to solving decision-making problems (Azadeh \& Izadbakhsh, 2008; Dos Santos et al., 2019). During the decision-making and prediction of possible results, managers usually face a complex system of interdependent components that should be analyzed, such as resources, goals, and employees. The strength of the AHP method lies in its ability to make impartial and sound classifications and in its flexibility in aggregating a set of parameters by defining their relative importance (Ma et al., 2019). The AHP method is traditionally used in selecting, prioritizing, and forecasting many decision-making problems. Moreover, it is widely used in various contexts. The AHP method has been used in studies with smaller samples (Al-Harbi, 2001; Chuc et al., 2020; Chiang et al., 2020; Tsyganok et al., 2012). Tsyganok et al. (2012) suggested that when using the AHP expert group, if the number of the members in the expert group is relatively high (more than 50 experts), the difference in expert abilities could be ignored (Chuc et al., 2020; Tsyganok et al., 2012). For groups with higher homogeneity, it is recommended that 15 to 30 experts be used to ensure accuracy. If the heterogeneity between members is high, 5 to 10 experts are sufficient (Chuc et al., 2020; Tsyganok et al., 2012). One of the techniques most widely used in a variety of contexts is the AHP (Chiang, 2019; Claver et al., 2020). The AHP assumes that decision-makers know or will devise-either individually or collectively, or implicitly or explicitly-the criteria or objectives and alternatives associated with the decision, e.g., the AHP supports decision-making for sustainable development (Dos Santos et al., 2019); building reuse (Claver et al., 2020) and real estate designs (Chiang, 2019). The AHP method has two advantages: (1) flexibility and intuitive appeal to decision-makers and (2) the ability to check for inconsistencies (Claver et al., 2020; Saaty, 1990; Wang, 2018). Principal AHP can be described as follows.

\section{STEP 1: Define the problems and set up a hierarchical structure}

The decision-makers can systematically evaluate the alternatives by making pairwise comparisons of each of the chosen factors. The most critical factors influencing the solution of the targeted problems are selected for the hierarchy architecture.

STEP 2: Establish a pairwise comparison matrix of criteria (A) from the relative importance scale

Calculate the degree of importance of each criterion using pairwise comparison and denote their relative importance on a numerical scale ranging from 1 to 9 .

$\mathrm{A}=\left[\begin{array}{cccc}a_{11} & a_{12} & \cdots & a_{1 n} \\ a & a_{22} & \cdots & a_{2 n} \\ \vdots & \vdots & \cdots & \vdots \\ a_{n 1} & a_{n 2} & \cdots & a_{n n}\end{array}\right]=\left[\begin{array}{cccc}w_{1} / w_{2} & w_{1} / w_{2} & \cdots & w_{1} / w_{n} \\ w_{2} / w_{1} & w_{2} / w_{2} & \cdots & w_{2} / w_{n} \\ \vdots & \vdots & \cdots & \vdots \\ w_{n} / w_{1} & w_{n} / w_{2} & \cdots & w_{n} / w_{n}\end{array}\right]$
$a_{i j}=1 / a_{i j}, a_{i j}=a_{j k} / a_{j k}, a_{i j} \neq 0, i, j=1,2,3 \cdots n . \quad(1)$

STEP 3: Calculate the eigenvalue $(\lambda)$ and eigenvector $(X)$ using Equations (3) and (4)

$$
A X=\lambda_{\max } X,(A-\lambda I) X=0,
$$

where $\lambda_{\max }$ is the largest eigenvalue of $\mathrm{A}$.

STEP 4: Check the Consistency Index (CI) and Consistency Ratio (CR)

$$
\begin{aligned}
& \text { Consistency Index }(\mathrm{CI})=\frac{\lambda_{\max }-n}{n-1} ; \\
& \text { Consistency Ratio (CR) }=\frac{C I}{R I} .
\end{aligned}
$$

The Random Index (RI) values, from the randomization index, are presented in Table 1.

Table 1. Randomization index values (Satty, 1990)

\begin{tabular}{|c|c|c|c|c|c|}
\hline $\mathrm{N}$ & 1 & 2 & 3 & 4 & 5 \\
\hline R.I. & 0 & 0 & 0.58 & 0.9 & 1.12 \\
\hline $\mathrm{N}$ & 6 & 7 & 8 & 9 & 10 \\
\hline R.I. & 1.24 & 1.32 & 1.41 & 1.45 & 1.49 \\
\hline
\end{tabular}

The results for consistency may be considered reliable only when the value of $\mathrm{CR}>0.1$. If $\mathrm{CR}>0.1$, the evaluation should be repeated to improve its consistency. As a final step, these priorities are synthesized to obtain the overall priority for each alternative, from which the alternative with the highest priority is ultimately selected.

\section{Data analysis methods}

\subsection{Questionnaire design}

By conducting a literature review, this study developed a questionnaire for assessing property management service quality. After compiling useful factors for space planning 
from the relevant literature, the study applied the FDM to collect experts' and scholars' opinions (Chiang \& Perng, 2018; Landeta et al., 2011). The collected opinions were later used to determine the evaluation factors. Compared with non-experts, experts are usually able to provide more insightful is possessing insight. Specifically, the experiences of experts with specialized skills are considerably more valuable than those of non-experts. The fundamental structure of the questionnaire, based on SERVQUAL and enhanced by Parasuraman et al. (1988), was designed specifically to analyze the cognitive gap between consumers and service providers. There were 21 team members of FDM, namely, 8 specialists in the industry including architects and real estate appraisers, 5 executives with who had doctorates, 4 directors of government sectors, and 4 professors from prestigious universities. The policy of property management was developed and amended by the Department of Urban Development. Regulations of the property management department are explicit and thus, it was easy to select appropriate experts and scholars. Two government directors and two professors were principal specialists in this field. They assisted in designing the questionnaire and advised the researcher so as to gain complete and effective data. Accordingly, this study conducted analyses on the basis of information obtained by (1) reviewing the relevant literature (ex: Chiang \& Perng, 2018; Dabholkar et al., 1996; Das et al., 2010; Garg \& Deshmukh, 2006; Peloza \& Shang, 2011; Perry \& Lindell, 2003; Tu, 2017; Zhang et al., 2019 ) and (2) examining service items commonly provided by the real estate industry and hotel industry to clients seeking residential planning services; the findings of such analyses served as the basis for decision implementation. Subsequently, experts and scholars from the property management service, building design, and real estate industries as well as high-ranking managers were interviewed and invited to revise the selected factors and propose potentially overlooked factors. Among them, (Community landscape services (X2), Secure parking areas (X3), Craftsman services (X9), Promptness in taking corrective actions when faults occur (X13), Business execution and degree of return (X14) and Active problem solving (X24)) are the new standards proposed by the FDM experts. Experts attached the most importance to security access control and household privacy and proposed that property management companies should be proactive in promoting them, and combined the above factors with innovative technology and the Internet, artificial intelligence, and big data; and suggested the elimination of traditional housekeeping ideas of property services; and providing high-quality service experience. The selected and newly added factors were then compiled and incorporated into a 25-item questionnaire (Table 2).

\subsection{FDM-based expert questionnaire survey}

This study established the evaluation factors for PMSP on the basis of the opinions of experts and scholars. According to Ishikawa et al. (1993) Delphi panels typically have a small sample size. If a sample is highly homo-
Table 2. Factors for assessment criteria items

\begin{tabular}{|c|c|}
\hline $\begin{array}{l}\text { Project } \\
\text { aspect }\end{array}$ & Related factor \\
\hline \multirow[t]{5}{*}{ Tangibles } & Case based learning (X1) \\
\hline & Community landscape services (X2) \\
\hline & Secure parking areas (X3) \\
\hline & Maintenance management (X4) \\
\hline & Community targeting (X5) \\
\hline \multirow[t]{5}{*}{ Reliability } & Staff retention $(\mathrm{X} 6)$ \\
\hline & Community defense mechanism (X7) \\
\hline & Implement project control (X8) \\
\hline & Craftsman services (X9) \\
\hline & Right attitudes and professional practices (X10) \\
\hline \multirow{5}{*}{$\begin{array}{l}\text { Respon- } \\
\text { siveness }\end{array}$} & Public safety violations (X11) \\
\hline & $\begin{array}{l}\text { Sound management of agent and house viewing } \\
\text { (X12) }\end{array}$ \\
\hline & $\begin{array}{l}\text { Promptness in taking corrective actions when } \\
\text { faults occur (X13) }\end{array}$ \\
\hline & Business execution and degree of return (X14) \\
\hline & Emergency preparedness (X15) \\
\hline \multirow[t]{5}{*}{ Assurance } & Hotel management (X16) \\
\hline & Strict access control (X17) \\
\hline & Equipment inspection services (X18) \\
\hline & Rescue and education (X19) \\
\hline & Brand image (X20) \\
\hline \multirow[t]{5}{*}{ Empathy } & Corporate social responsibility (X21) \\
\hline & Neighborhood events (X22) \\
\hline & Protection of residents' privacy (X23) \\
\hline & Active problem solving (X24) \\
\hline & Community involvement (X25) \\
\hline
\end{tabular}

geneous, the sample size should be $15-30$ members; if a sample is adequately heterogeneous, the sample size should be 5-10 (Ishikawa et al., 1993; Landeta et al., 2011). Because the sample of experts selected in this study was homogenous, this study applied the aforementioned sampling criterion and selected 21 team members. Copies of the questionnaire were distributed to the participating experts through e-mail, postal mail, or personal delivery. The questionnaire completion progress was monitored through phone calls. The questionnaire survey was conducted between September 2018 and October 2019. After the data collection process was completed, the FDM was applied to screen the factors. The analytical results were useful in refining the questionnaire items and deleting any factors that did not have sufficient discriminatory power. In general, the experts' consensus regarding a factor was evaluated using the measure measures $G^{i}$. A higher $G^{i}$ value for a specific factor indicates a greater consensus among the experts with regard to the factor. Therefore, such factors were considered to be more suitable for inclusion in the evaluation factor set. FDM has been 
proved to utilize triangular fuzzy numbers to integrate the cognition of experts and scholars, and improve the limitations of the traditional Delphi method, which could only provide $50 \%$ of the information because of the repeated questionnaire survey. FDM has the advantage of semantically expressing the meaning more precisely (Wang \& Peng, 2020). Therefore, the triangular membership function and fuzzy theory was applied to classify the appraisal factors to select property service.

FDM was applied for factor screening to remove factors with a low discrimination index and simplify the questionnaires further. The analysis results are shown in (Table 3); there was an expert consensus threshold value $\left(G^{i}\right)$ of 6.91. Two factors, namely, Sound management of agent and house viewing (X12) and Neighborhood events (X22) had a value less than 6.91 and were thus removed; 23 factors remained.

\section{Analysis of empirical data}

\subsection{AHP framework and expert questionnaire description}

From the literature review and interviews with FDM expert groups, most studies have focused only on industry players in conducting AHP decision analysis. However, with the rise in consumer awareness and service science, management of service quality has become increasingly important. AHP is applied to determine the service items and measurement criteria that best reflect customer needs and establish a customer preference factor structure for the reference of property management providers. AHP decomposes complicated problems into a hierarchy and allows pair-wise comparisons of every criterion to calculate their relative importance.

In the first stage, the FDM technology enables the improvement of the efficiency of group decision-making. It is also a research method that negotiates expert group opinions and solves group decision-making problems by means of triangular membership functions and fuzzy set theory to achieve a consensus within an expert group, appraisal factors to select property service. In the second stage, the AHP was applied to analyze data from the expert questionnaire survey. The AHP was divided into two sub-stages. The first sub-stage involved conducting a consistency check on the evaluation results of each expert. This check was conducted to ensure the validity of the questionnaire responses and the evaluation results of each expert. The second sub-stage entailed integrating service providers' opinions to determine the weight and ranking of each evaluation factor and consequently improve the

Table 3. Analysis of the FDM statistics

\begin{tabular}{|c|c|c|c|c|c|c|c|}
\hline \multirow{2}{*}{ Factors } & \multicolumn{3}{|c|}{ Conservative value } & \multicolumn{3}{|c|}{ Optimistic value } & \multirow{2}{*}{$G^{i}$} \\
\hline & $C_{L}^{i}$ & $C_{U}^{i}$ & $C_{M}^{i}$ & $O_{L}^{i}$ & $O_{U}^{i}$ & $O_{M}^{i}$ & \\
\hline $\mathrm{X} 1$ & 4 & 7 & 5.14 & 7 & 10 & 8.38 & 7.00 \\
\hline $\mathrm{X} 2$ & 5 & 7 & 6.10 & 8 & 10 & 8.43 & 7.68 \\
\hline $\mathrm{X} 3$ & 4 & 8 & 5.57 & 6 & 10 & 8.19 & 6.95 \\
\hline $\mathrm{X} 4$ & 4 & 8 & 5.81 & 7 & 10 & 8.10 & 7.33 \\
\hline $\mathrm{X} 5$ & 4 & 7 & 5.52 & 7 & 9 & 8.38 & 7.00 \\
\hline $\mathrm{X} 6$ & 4 & 8 & 5.86 & 6 & 10 & 8.10 & 6.99 \\
\hline $\mathrm{X} 7$ & 4 & 7 & 5.62 & 7 & 10 & 8.43 & 7.00 \\
\hline $\mathrm{X} 8$ & 5 & 8 & 6.05 & 7 & 10 & 8.57 & 7.45 \\
\hline X9 & 4 & 8 & 6.00 & 7 & 10 & 8.43 & 7.42 \\
\hline $\mathrm{X} 10$ & 5 & 8 & 6.10 & 7 & 10 & 8.29 & 7.40 \\
\hline $\mathrm{X} 11$ & 3 & 8 & 5.76 & 6 & 10 & 8.00 & 6.94 \\
\hline $\mathrm{X} 12$ & 4 & 7 & 5.57 & 6 & 10 & 8.10 & 6.60 \\
\hline $\mathrm{X} 13$ & 5 & 8 & 6.33 & 7 & 10 & 8.81 & 7.52 \\
\hline X14 & 5 & 8 & 6.14 & 7 & 10 & 8.29 & 7.41 \\
\hline X15 & 5 & 8 & 6.14 & 7 & 10 & 8.62 & 7.47 \\
\hline X16 & 4 & 7 & 5.71 & 7 & 9 & 8.00 & 7.00 \\
\hline $\mathrm{X} 17$ & 4 & 8 & 6.10 & 7 & 10 & 8.86 & 7.49 \\
\hline X18 & 4 & 8 & 6.14 & 6 & 10 & 8.71 & 7.19 \\
\hline X19 & 5 & 8 & 6.00 & 7 & 10 & 8.90 & 7.49 \\
\hline X20 & 4 & 8 & 5.95 & 6 & 10 & 8.43 & 7.09 \\
\hline $\mathrm{X} 21$ & 4 & 8 & 5.86 & 7 & 10 & 8.29 & 7.38 \\
\hline $\mathrm{X} 22$ & 3 & 7 & 5.48 & 6 & 9 & 7.95 & 6.56 \\
\hline X23 & 4 & 8 & 5.95 & 6 & 10 & 8.62 & 7.12 \\
\hline X24 & 4 & 7 & 5.86 & 7 & 10 & 8.52 & 7.00 \\
\hline X25 & 4 & 8 & 5.76 & 6 & 10 & 8.00 & 6.94 \\
\hline
\end{tabular}


reliability of the items, rendering the findings to be more objective and appropriate as well as consistent with actual needs; this sub-stage was essential in ensuring that the evaluation results were objective, applicable, and met actual needs. The questionnaire survey results could be applied in future PMSP processes.

\subsection{Item testing and object of survey}

This study involved the assumption that customer and business operators differ with respect to their perceptions of property management service items. A total of 30 questionnaires were distributed to the participants, namely high-ranking managers or experts and scholars with working experience in the property management industry. This study recruited participants with relevant interests to the study topic. Because high-end customers (i.e., residents) belong to the top stratum of the social pyramid and pay special attention to privacy and security, it is extremely difficult to conduct AHP surveys. At the same time, they usually have a level of understanding and insight beyond ordinary people in terms of management and service quality.

\section{Property service provider sample description}

The sample selected consists of 30 people who are managers from property services firms, heads of community management committees.

\section{Customer sample description}

The property management industry is concentrated in Shanghai metropolitan areas. Conditions of talent, capital, resource, and industrial allocation vary as well; medium and high-floor residential communities have a higher demand for property management. Therefore, the study focused on customers who have been living in residential communities for two years or more in Chengdu metropolitan areas and the corresponding property management companies.

\subsection{Analysis and verification of AHP questionnaire data}

According to Chiang, the AHP requires at least a year to yield results with a necessary level of consistency (Chiang, 2019). In using the AHP method, we decided to use a numeric scale (i.e., a Saaty scale) between 1 and 9 , which was used to assign weights to standards, sub-standards, and alternative methods. The first step was to compare the standards and sub-standards. In the next step, we compared each alternative with the standards and sub-standards and then calculated the overall priority of the standards, substandards, and alternatives. This study took more than a year to complete, and had a very rigorous approach during the research process. As such, the results and conclusions from our questionnaire meet a certain standard. The questionnaire data passed the consistency test (i.e., $\mathrm{CR} \leq 0.1$ ). The data from which were used to calculate the relative weighting values of the five dimensions (Table 4).

Table 4. Relative weights of major criteria and minor criteria

\begin{tabular}{|c|c|c|c|c|c|}
\hline Criteria & Level (1) $W_{i}$ & Sub-criteria & Level (2) $W_{i}$ & Overall $W_{i}$ & $\begin{array}{r}\text { Overall } \\
\text { sequence }\end{array}$ \\
\hline \multirow[t]{5}{*}{ Tangibles } & \multirow[t]{5}{*}{20.84} & Case based learning (X1) & $20.28 \%$ & $4.06 \%$ & 15 \\
\hline & & Community landscape services (X2) & $21.27 \%$ & $4.25 \%$ & 13 \\
\hline & & Secure parking areas (X3) & $19.99 \%$ & $4.00 \%$ & 16 \\
\hline & & Maintenance management (X4) & $21.28 \%$ & $4.26 \%$ & 12 \\
\hline & & Improving community (X5) & $17.17 \%$ & $3.44 \%$ & 21 \\
\hline \multirow[t]{5}{*}{ Reliability } & \multirow[t]{5}{*}{20.22} & Staff retention $(\mathrm{X} 6)$ & $15.24 \%$ & $3.05 \%$ & 22 \\
\hline & & Community defense mechanism (X7) & $26.42 \%$ & $5.28 \%$ & 4 \\
\hline & & Implement project control (X8) & $21.10 \%$ & $4.22 \%$ & 14 \\
\hline & & Craftsman services (X9) & $17.40 \%$ & $3.48 \%$ & 20 \\
\hline & & Right attitudes and professional practices (X10) & $19.84 \%$ & $3.97 \%$ & 17 \\
\hline \multirow[t]{4}{*}{ Responsiveness } & \multirow[t]{4}{*}{18.19} & Public safety violations (X11) & $24.14 \%$ & $4.83 \%$ & 8 \\
\hline & & $\begin{array}{l}\text { Promptness in taking corrective actions when faults } \\
\text { occur (X13) }\end{array}$ & $25.35 \%$ & $5.07 \%$ & 5 \\
\hline & & Business execution and degree of return (X14) & $23.80 \%$ & $4.76 \%$ & 9 \\
\hline & & Emergency preparedness (X15) & $26.71 \%$ & $5.34 \%$ & 2 \\
\hline \multirow[t]{5}{*}{ Assurance } & \multirow{5}{*}{21.92} & Hotel management (X16) & $14.87 \%$ & $2.97 \%$ & 23 \\
\hline & & Strict access control (X17) & $26.68 \%$ & $5.34 \%$ & 3 \\
\hline & & Equipment inspection services (X18) & $21.67 \%$ & $4.33 \%$ & 11 \\
\hline & & Rescue and education (X19) & $17.54 \%$ & $3.51 \%$ & 19 \\
\hline & & Brand image (X20) & $19.23 \%$ & $3.85 \%$ & 18 \\
\hline \multirow[t]{4}{*}{ Empathy } & \multirow[t]{4}{*}{18.83} & Corporate social responsibility (X21) & $24.52 \%$ & $4.91 \%$ & 6 \\
\hline & & Protection of residents' privacy (X23) & $27.52 \%$ & $5.50 \%$ & 1 \\
\hline & & Active problem solving (X24) & $24.20 \%$ & $4.84 \%$ & 7 \\
\hline & & Community involvement (X25) & $23.76 \%$ & $4.75 \%$ & 10 \\
\hline \multicolumn{2}{|l|}{$W_{i}=W_{i} \times 100 \%$} & & - & $100.00 \%$ & - \\
\hline
\end{tabular}




\section{Discussion}

\subsection{Customer and property manager weighted data analysis}

The order that service assurance and tangibles appear within the five dimensions is similar, indicating their similarity in principle to others in the domain, and firms' ability to deliver on their promise of customer service. AHP generally decomposes complicated problems into a hierarchy, then performs pair-wise comparisons of every criterion to calculate their relative importance (Chiang, 2019; Wang, 2018). Overall, the "service assurance" dimension is viewed as the most important, but "tangibles tangibility" matters most to the actual customer, indicating that the industry needs to pay closer attention to customer psychology. Personalized service and experience are more important than facilities and command greater customer attention. The differences in the overall ranking are taken from (Table 5).

The rankings in the first customer hierarchy are ordered as: assurance, empathy, reliability, responsiveness and tangibles. The ordering of the second is: X7, X23, X17, X15, X13. While, the ranking of first provider hierarchy is: assurance, empathy, responsiveness, reliability and tangibles. The ranking of the second is: $\mathrm{X} 23, \mathrm{X} 15, \mathrm{X} 17, \mathrm{X} 7, \mathrm{X} 13$.

There are two corresponding dimensions that have certain differences within the five major dimensions; tangibles and assurance. Tangibles shows that experts deem the physical equipment and employee image aspects of the service to be the most important and value them slightly higher than average. Assurance is the service staff's knowledge, politeness and ability to win customer confidence and trust, which places slightly lower than average. Empathy is comprehensive and timely services offered to customers that affords them a sense of familiarity and intimacy. In the relationship between the customer requesting improvement of the property management company's and depth of understanding, responsiveness and tangibles as service quality is somewhat weak. This affects the customer's behavioral intention, thus there is a need to indirectly reduce the degree of attention placed on the customer's behavioral intention as well as customer satisfaction through a living environment experience. A "customer-oriented" perspective should be adopted to improve the relationship with customers through normal complaint handling and feedback, to improve service performance.

Table 5. Weight order of the AHP overall evaluation index (customer ratings)

\begin{tabular}{|c|c|c|c|c|c|}
\hline Criteria & Sub-criteria & Overall $W_{i}(1)$ & Overall $W_{i}(2)$ & Overall sequence (1) & Overall sequence (2) \\
\hline \multirow[t]{5}{*}{ Tangibles } & $\mathrm{X} 1$ & $4.10 \%$ & $4.01 \%$ & 15 & 15 \\
\hline & $\mathrm{X} 2$ & $4.21 \%$ & $4.30 \%$ & 14 & 11 \\
\hline & $\mathrm{X} 3$ & $4.00 \%$ & $4.00 \%$ & 16 & 16 \\
\hline & $\mathrm{X} 4$ & $4.30 \%$ & $4.21 \%$ & 13 & 13 \\
\hline & $\mathrm{X} 5$ & $3.39 \%$ & $3.48 \%$ & 20 & 21 \\
\hline \multirow[t]{5}{*}{ Reliability } & X6 & $2.74 \%$ & $3.38 \%$ & 23 & 22 \\
\hline & $\mathrm{X} 7$ & $5.54 \%$ & $5.03 \%$ & 1 & 4 \\
\hline & $\mathrm{X} 8$ & $4.39 \%$ & $4.04 \%$ & 12 & 14 \\
\hline & $\mathrm{X} 9$ & $3.39 \%$ & $3.57 \%$ & 21 & 19 \\
\hline & $\mathrm{X} 10$ & $3.94 \%$ & $3.99 \%$ & 17 & 17 \\
\hline \multirow[t]{4}{*}{ Responsiveness } & $\mathrm{X} 11$ & $4.76 \%$ & $4.89 \%$ & 9 & 8 \\
\hline & $\mathrm{X} 13$ & $5.17 \%$ & $4.97 \%$ & 5 & 5 \\
\hline & $\mathrm{X} 14$ & $4.89 \%$ & $4.63 \%$ & 7 & 9 \\
\hline & $\mathrm{X} 15$ & $5.18 \%$ & $5.51 \%$ & 4 & 2 \\
\hline \multirow[t]{5}{*}{ Assurance } & $\mathrm{X} 16$ & $2.86 \%$ & $3.09 \%$ & 22 & 23 \\
\hline & $\mathrm{X} 17$ & $5.39 \%$ & $5.28 \%$ & 3 & 3 \\
\hline & $\mathrm{X} 18$ & $4.42 \%$ & $4.24 \%$ & 11 & 12 \\
\hline & X19 & $3.48 \%$ & $3.54 \%$ & 19 & 20 \\
\hline & $\mathrm{X} 20$ & $3.84 \%$ & $3.85 \%$ & 18 & 18 \\
\hline \multirow[t]{4}{*}{ Empathy } & $\mathrm{X} 21$ & $4.89 \%$ & $4.92 \%$ & 8 & 7 \\
\hline & $\mathrm{X} 23$ & $5.45 \%$ & $5.55 \%$ & 2 & 1 \\
\hline & $\mathrm{X} 24$ & $5.08 \%$ & $4.61 \%$ & 6 & 10 \\
\hline & $\mathrm{X} 25$ & $4.58 \%$ & $4.93 \%$ & 10 & 6 \\
\hline Total & - & $100.00 \%$ & $100.00 \%$ & - & - \\
\hline
\end{tabular}

Note: Overall sequence (1) Customer, (2) Business operators. 


\subsection{Similarities and differences between respondents}

It can be seen from the (Table 5), that in the weight ranking of the five major dimensions, the PMSP dimension-assurance is weighted the highest. Property management services deem the assurance dimensions of strict security and access control to be of great importance, indicating that they place a great deal of value on assurance. The second highest is empathy. Privacy protection for residents should be provided through the establishment of comprehensive monitoring system equipment that provides strict security access allows residents complete and total assurance, and effectively protects their privacy without threat of infringement. Meanwhile, the dimensions that the customers value most highly are the same as those of the property management services. Tangibles is the image of physical equipment and employees projected where services occur. The top ten factors ranked within the overall indicators from customers and property service providers are, Customers: X7, X23, X17, X15, X13, X24, X14, X21, X11, X25; Property Service Firms: X23, X15, X17, X7, X13, X25, X21, X11, $\mathrm{X} 14, \mathrm{X} 24$. In the assessment the assurance and empathy dimensions are given great weight, showing little difference within the overall results. After arranging the similarities and differences of customers and property service firms into combined hierarchies, the similarities in the highest second-level indicators were concentrated in the tangibles dimension that represents physical equipment and includes service provision. The research aspect is assurance and empathy dimensions are given great weight, this study established 23 items, including significant differences in X6 and $\mathrm{X} 7$, showing little difference within the overall results. The image of tools, equipment and employees is the ranked most important for customers; the most important indicators in PMSP are: X15, X17, X23.

\subsection{Establishing improvement strategies}

According to the analysis in Table 5, there is a tremendous gap in the "X16, X6" part of the scale that analyzes customer and property service providers (Figure 2 and
Table 5). There is a significant gap in "X16, X6, X5, X19". Thus, the proposed improvement strategy is as follows:

- Hotel management (X16): Through expert interviews, it was found that households or customers often have their service staff and may not need this type of service. Property management companies should implement this type of service to avoid any effect on the management of public areas and resident's privacy. Therefore, it is essential to focus on safety, oversight, and management.

- Staff retention (X6) was less: Community affairs management can maintain greater stability with less staff turnover and on-site personnel having a good relationship with the community residents, enabling them to provide higher levels of care. It will also not be subject to frequent personnel changes that affect the operation of community affairs, reducing residents' distrust in property management companies. To provide property services for residents and clients that are on par with existing quality standards, property management services should employ more qualified service personnel and regularly educate and train them.

- Improving community targeting rate (X5) was less: On-site personnel interact with community residents and give them special attention and respect, and members are, to some extent, the opinion leaders among the households, which are the main customer group. Property management companies should organize "community association meetings" regularly to enhance affection, promote their interactions with community residents, and understand the characteristics of each community, thereby interacting with each other and enhancing community spirit.

- Rescue and education (X19) rate was less: Companies urgently need to implement a standardized disaster prevention system during peacetime; this will enable regional groups to play the role of mutual supporters and provide aid, timely support, and rapid resettlement during disasters. Property management companies should assist and strengthen firefighting public

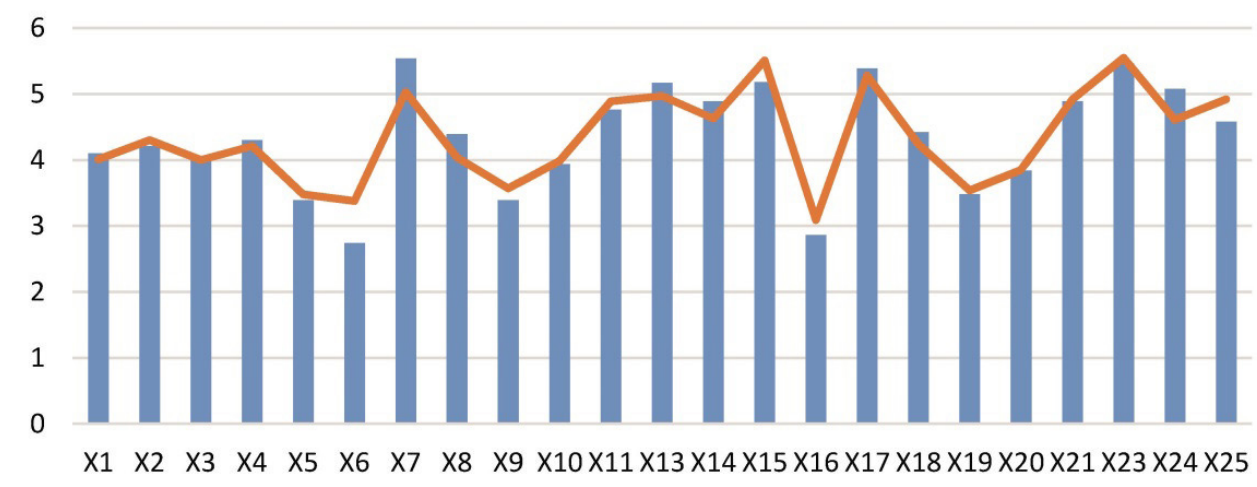

Customer Business operators

Figure 2. Customer and business operators weighting map 
relations measures and emergency evacuation guidance safety drills. Moreover, the community should implement an annual fire safety drill; the local fire brigade should be invited so that the residents will be familiar with fire equipment in the building and the escape measures.

Regarding its theoretical implications, this study contributes to the literature about the effect of service quality and consumer response on suppliers in the property management industry. Thus, this study's conceptual model may serve as a reference for other researchers interested in examining the effect of service quality on consumers and suppliers. Regarding its management significance, providing reliable products and services is a crucial factor that must be adequately addressed. Customers evaluate the reliability of property management companies. Because the property management industry is highly competitive, any slack or shortcoming in a company's reliability may lead to undesirable results. Therefore, external measures, such as short personal interviews, online or telephone surveys, and email feedback, are suitable alternatives. Considering this feedback, PMSP is essential to implement measures to mitigate any shortcomings to maintain a high degree of reliability. They must periodically change their strategies to meet the needs of and satisfy customers. When customers are impressed by high professional standards, it affects their willingness to use a service. This is consistent with the results in the study by Chiang and Perng (2018). In the "retention rate" dimension, when management pays for a full-scale quality property service staff and regularly educates and trains them to meet customers' expectations, different services can be provided to address the needs of various customer groups, thereby enhancing willingness to re-use the service.

\section{Conclusions}

Understanding the needs and expectations of customers is a critical factor for the success of enterprises, which include all types of commercial organizations. High customer satisfaction enhances customer loyalty and creates a sustainable competitive advantage in a saturated market (Chiang \& Perng, 2018; Saeidi et al., 2015). To provide quality service that meets the needs of the site, property management companies should highly value and adopt the recommendations of management committees and individual managers. Thus, on-site property management companies should make ongoing adjustments, provide quality service, and facilitate joint service improvement. Quality creates value. Companies should uphold professionalism as a benchmark to meet the expectations of community management committees. Property management companies should demonstrate professionalism, efficiency, communication, and education to serve the community and enhance residents' satisfaction with the quality of their services. Through this assessment, community management committees can examine and evaluate property management services and reduce unnecessary ser- vices, thereby increasing customer satisfaction and reducing complaints. Regarding the PMSP evaluators, "service differentiation" and "low cost," should be implemented, so that even with limited resources, property management services can reach more effective service distribution, reduce unnecessary costs, and implement optimal plans. The new crown pneumonia epidemic has comprehensively tested the emergency response and management abilities as well as the prevention and control system of property management companies. Moreover, it has also become the benchmark for distinguishing high-quality and ordinary properties. The high-quality service, brand value, and social responsibility that a property management company exhibits in preventing and controlling disasters can rapidly expand the company. In the medium and long term, the benchmarking agreement can foster a high-quality property management culture in Shanghai because poorly performing property management companies will be eliminated by market forces. This effect will be positive in the long term, and it can quickly accumulate more capital and experience for future development. Finally, the effect on management should be evaluated according to each specific situation. Different methods should be adopted to address various concerns with unique characteristics, including local culture; business practices; the structure of community committees; and differences in region, time, and market sentiment. Thus, only the most appropriate management will remain-not the best management. The cluster in the property management industry promotes local economic development through existing supply chain networks. It is essential to protect the safety of residents, facilities, and equipment. Services such as basic repairs and maintenance are only provided by local suppliers or managed by internal personnel to contribute to the local economy and create various service categories. With regard to employment opportunities, the property management structure is complex; has many business relationships; and utilizes a wide range of human resources, products, and services. Moreover, there should be a more indepth analysis of the property management supply chain in future research. This will enable the public and business owners to better understand how the property management industry stimulates other industries and highlight the potential adverse effects of related departments. The property management industry is in crisis. This study proves that the potential crisis in the property management industry that will affect Shanghai; it is also obvious that this crisis will also have a regional and national effect.

\section{References}

Al-Harbi, K. M. A.-S. (2001). Application of the AHP in project management. International Journal of Project Management, 19(1), 19-27. https://doi.org/10.1016/S0263-7863(99)00038-1

Azadeh, A., \& Izadbakhsh, H. R. (2008). A multi-variate/multiattribute approach for plant layout design. International Journal of Industrial Engineering: Theory, Applications and Practice, 15(2), 143-154. 
Bouzon, M., Govindan, K., Rodriguez, C. M. T., \& Campos, L. M. (2016). Identification and analysis of reverse logistics barriers using fuzzy Delphi method and AHP. Resources, Conservation and Recycling, 108, 182-197.

https://doi.org/10.1016/j.resconrec.2015.05.021

Chen, C.-A. (2016). How can Taiwan create a niche in Asia's cruise tourism industry? Tourism Management, 55, 173-183. https://doi.org/10.1016/j.tourman.2016.02.015

Chen, W. T., You, J.-K., \& Chen, H. L. (2015). Critical success factors of construction site safety management in Taiwan. Construction Engineering, 3, 30-35.

Chiang, T.-Y. (2019). Real estate developer's product positioning: AHP-utility-based model. International Journal of Strategic Property Management, 23(5), 317-327. https://doi.org/10.3846/ijspm.2019.9752

Chiang, T.-Y., \& Perng, Y.-H. (2018). A new model to improve service quality in the property management industry. International Journal of Strategic Property Management, 22(5), 436-446. https://doi.org/10.3846/ijspm.2018.5226

Chiang, T.-Y., Chu, C.-C., Shen, H.-M., \& Chiu, Y.-F. (2020). A gid utility-based model for interior renovations selection. Journal of Asian Architecture and Building Engineering, 1-11. https://doi.org/10.1080/13467581.2020.1787174

Chuc, A. T., Sarker, T., \& Rasoulinezhad, E. (2020). Factors influencing the green bond market expansion: evidence from a multi-dimensional analysis. Journal of Risk and Financial Management, 13(6), 126.

https://doi.org/10.3390/jrfm13060126

Claver, J., García-Domínguez, A., \& Sebastián, M. A. (2020). Multicriteria decision tool for sustainable reuse of industrial heritage into its urban and social environment. Case studies. Sustainability, 12(18), 7430.

https://doi.org/10.3390/su12187430

Dabholkar, P. A., Thorpe, D. I., \& Rentz, J. O. (1996). A measure of service quality for retail stores: scale development and validation. Journal of the Academy of Marketing Science, 24(1), 3-16. https://doi.org/10.1007/BF02893933

Das, A., Kumar, V., \& Saha, G. C. (2010). Retail service quality in context of CIS countries. International Journal of Quality \& Reliability Management, 27(6), 658-683. https://doi.org/10.1108/02656711011054542

Dos Santos, P. H., Neves, S. M., Sant'Anna, D. O., de Oliveira, C. H., \& Carvalho, H. D. (2019). The analytic hierarchy process supporting decision making for sustainable development: an overview of applications. Journal of Cleaner Production, 212, 119-138.

https://doi.org/10.1016/j.jclepro.2018.11.270

Garg, A., \& Deshmukh, S. G. (2006). Maintenance management: literature review and directions. Journal of Quality in Maintenance Engineering, 12(3), 205-238.

https://doi.org/10.1108/13552510610685075

Goss, R. C., \& Campbell, H. L. (2008). The evolution of residential property management: from caretaker to income maximization managers. Housing and Society, 35(1), 5-20. https://doi.org/10.1080/08882746.2008.11430555

Hopkins, E. A., Read, D. C., \& Goss, R. C. (2017). Promoting sustainability in the United States multifamily property management industry. Journal of Housing and the Built Environment, 32(2), 361-376. https://doi.org/10.1007/s10901-016-9516-3

Ishikawa, A., Amagasa, M., Shiga, T., Tomizawa, G., Tatsuta, R., \& Mieno, H. (1993). The max-min Delphi method and fuzzy Delphi method via fuzzy integration. Fuzzy Sets and Systems, 55(3), 241-253.

https://doi.org/10.1016/0165-0114(93)90251-C
Kendra, K., \& Taplin, L. J. (2004). Project success: a cultural framework. Project Management Journal, 35(1), 30-45. https://doi.org/10.1177/875697280403500104

Landeta, J., Barrutia, J., \& Lertxundi, A. (2011). Hybrid Delphi: a methodology to facilitate contribution from experts in professional contexts. Technological Forecasting and Social Change, 78(9), 1629-1641. https://doi.org/10.1016/j.techfore.2011.03.009

Ma, L., Liu, Z., Huang, X., \& Li, T. (2019). The impact of local government policy on innovation ecosystem in knowledge resource scarce region: case study of Changzhou, China. Science, Technology and Society, 24(1), 29-52.

https://doi.org/10.1177/0971721818806096

Murray, T. J., Pipino, L. L., \& van Gigch, J. P. (1985). A pilot study of fuzzy set modification of Delphi. Human Systems Management, 5(1), 76-80. https://doi.org/10.3233/HSM-1985-5111

Omar, M., Ali, H. M., Kamaruddin, N., Baba, M., Sapri, M., Abdullah, S., \& Aliagha, G. U. G. (2015). Framework of stratified residential property management services. Jurnal Teknologi, 75(10), 57-64. https://doi.org/10.11113/jt.v75.5273

Parasuraman, A., Zeithaml, V. A., \& Berry, L. L. (1985). A conceptual model of service quality and its implications for future research. Journal of Marketing, 49(4), 41-50. https://doi.org/10.1177/002224298504900403

Parasuraman, A., Zeithaml, V. A., \& Berry, L. L. (1988). SERVQUAL: a multiple-item scale for measuring consumer perceptions of service quality. Journal of Retailing, 64(1), 12-37.

Peloza, J., \& Shang, J. (2011). How can corporate social responsibility activities create value for stakeholders? A systematic review. Journal of the Academy of Marketing Science, 39(1), 117-135. https://doi.org/10.1007/s11747-010-0213-6

Perry, R. W., \& Lindell, M. K. (2003). Preparedness for emergency response: guidelines for the emergency planning process. Disasters, 27(4), 336-350. https://doi.org/10.1111/j.0361-3666.2003.00237.x

Read, D. C., \& Carswell, A. (2019). Is property management viewed as a value-added service? Property Management, 37(2), 262-274. https://doi.org/10.1108/PM-05-2018-0034

Read, D. C., \& Sanderford, A. R. (2018). Sustaining sustainability in large real estate investment management firms. Journal of Real Estate Portfolio Management, 24(1), 19-33. https://doi.org/10.1080/10835547.2018.12090004

Read, D. C., Goss, R. C., \& Hopkins, E. (2017). Strategic business development and client prospecting in the third-party apartment management industry. International Journal of Strategic Property Management, 21(4), 346-356.

https://doi.org/10.3846/1648715X.2017.1317297

Saaty, T. L. (1990). How to make a decision: the analytic hierarchy process. European Journal of Operational Research, 48(1), 9-26. https://doi.org/10.1016/0377-2217(90)90057-I

Saeidi, S. P., Sofian, S., Saeidi, P., Saeidi, S. P., \& Saaeidi, S. A. (2015). How does corporate social responsibility contribute to firm financial performance? The mediating role of competitive advantage, reputation, and customer satisfaction. Journal of Business Research, 68(2), 341-350.

https://doi.org/10.1016/j.jbusres.2014.06.024

Tsyganok, V. V., Kadenko, S. V., \& Andriichuk, O. V. (2012). Significance of expert competence consideration in group decision making using AHP. International Journal of Production Research, 50(17), 4785-4792. https://doi.org/10.1080/00207543.2012.657967

Tu, K. J. (2017). Designing for sustainable public housing from property management and financial feasibility perspectives. International Journal of Architectural and Environmental Engineering, 11(2), 163-171. 
Wang, J.-W. (2018). Retrieving critical design factor of ebook for older people in Taiwan. Telematics and Informatics, 35(7), 2016-2027. https://doi.org/10.1016/j.tele.2018.07.005

Wang, W.-M., \& Peng, H.-H. (2020). A fuzzy multi-criteria evaluation framework for urban sustainable development. Mathematics, 8(3), 330. https://doi.org/10.3390/math8030330

Wang, Y. L., Luor, T., Luarn, P., \& Lu, H. P. (2015). Contribution and trend to quality research - a literature review of SERVQUAL model from 1998 to 2013. Informatica Economica, 19(1), 34-45. https://doi.org/10.12948/issn14531305/19.1.2015.03
Xie, C., Bagozzi, R. P., \& Grønhaug, K. (2019). The impact of corporate social responsibility on consumer brand advocacy: the role of moral emotions, attitudes, and individual differences. Journal of Business Research, 95, 514-530. https://doi.org/10.1016/j.jbusres.2018.07.043

Zadeh, L. A. (1965). Fuzzy sets. Information and Control, 8(3), 338-353. https://doi.org/10.1016/S0019-9958(65)90241-X

Zhang, Y., Shen, L., Ren, Y., Wang, J., Liu, Z., \& Yan, H. (2019). How fire safety management attended during the urbanization process in China? Journal of Cleaner Production, 236, 117686. https://doi.org/10.1016/j.jclepro.2019.117686 